\title{
Identification of susceptibility loci for Type 1 (insulin-dependent) diabetes by trans-racial gene mapping
}

\author{
D.Jenkins ${ }^{1}$, C. Mijovic ${ }^{1}$, J. Fletcher ${ }^{1}$, K. H. Jacobs ${ }^{1}$, A. R. Bradwell ${ }^{2}$ and A. H. Barnett ${ }^{1}$ \\ Departments of ${ }^{1}$ Medicine and ${ }^{2}$ Immunology, University of Birmingham and East Birmingham Hospital, Birmingham, U. K.
}

\begin{abstract}
Summary. A major component of inherited susceptibility to Type 1 (insulin-dependent) diabetes mellitus has been mapped to the major histocompatibility complex. Certain gene alleles in this region determine susceptibility and resistance to the disease. Mapping of susceptibility is hindered by the limitations of conventional tissue typing techniques, and by strong linkage disequilibrium within this part of the genome. Recombinant DNA technology and trans-racial
\end{abstract}

studies have been used to allow finer mapping of genetic predisposition to Type 1 diabetes. These techniques have localised alleles encoding susceptibility and resistance to the DQ region. Other alleles determining disease susceptibility remain poorly localised.

Key words: Type 1 diabetes, trans-racial studies, DNA, gene mapping, HLA, MHC.
Type 1 (insulin-dependent) diabetes mellitus is an autoimmune disease of uncertain aetiology. Both environmental and genetic factors appear important. Inherited susceptibility has been mapped to the major histocompatibility complex (MHC), lying on the short arm of chromosome six. (The human MHC is also termed the HLA region). Non-MHC genes may determine up to $40 \%$ of inherited susceptibility to Type 1 diabetes [1], but little is known of their location [2]. This review considers which MHC genes may predispose to the disease, and the methods used to study genetic associations with Type 1 diabetes.

\section{Major histocompatibility complex (MHC)}

The MHC consists of several genes. They have been broadly classified into the HLA class I, II and III loci (Fig.1). Other genes within this region include the loci which encode C-21 hydroxylase [3], tumour necrosis factors [4], heat shock protein [5], and genes of unknown function [6]. More genes may exist in the unmapped portions of the MHC.

The MHC class I genes are subdivided into the A, B and $C$ loci. They encode $\alpha$-chains which combine with $\beta_{2^{-}}$ microglobulin to form glycoproteins found on the surfaces of nearly all cell types. These restrict cytotoxic T-cell activity.
The class II genes encode glycoproteins which occur on the surfaces of particular cell types, including macrophages, B-lymphocytes and activated T-lymphocytes. Class II molecules consist of an $\alpha$ - and a $\beta$-chain which are encoded by separate A and B genes. Each chain consists of cytoplasmic, trans-membrane and extracellular portions (Fig. 2). The extracellular portion is made up of first and second domains. The first domain interacts directly with the T-cell receptor, and is, therefore, critical to the function of the molecule. Class II molecules are subdivided into the DR, DQ and DP series, each encoded by distinct pairs of genes. Their functions include presentation of foreign antigen to the T-helper cell [7].

The class III genes encode the complement components $\mathrm{C} 2, \mathrm{C} 4$ and factor $\mathrm{B}$. Their genetics and polymorphisms have been reviewed $[8,9]$.

Many of the MHC genes exhibit considerable polymorphism, which is assumed to have arisen in response to the array of environmental pathogens. Polymorphism of the class I and II genes causes variation in the class I and II molecules possessed by different individuals. The associations of certain MHC gene polymorphisms (alleles) with Type 1 diabetes suggest that genes within this region determine disease susceptibility. The definition of MHC polymorphism is dependent on the technique used. The methods used are briefly described below. 


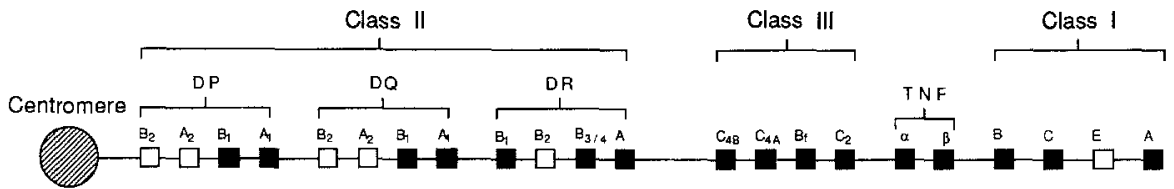

Fig. 1. Simplified diagram of the major histocompatibility complex on the short arm of chromosome 6. Expressed genes are shown as solid squares, while pseudogenes and genes of uncertain status are shown as open squares. The number of DRB genes varies between

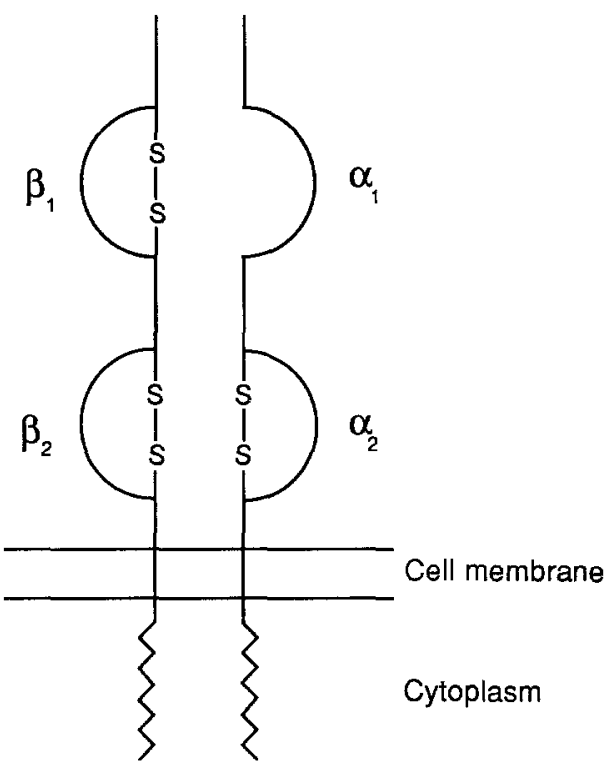

Fig. 2. Two-dimensional representation of the structure of a class II molecule. $\alpha 1$ and $\beta 1$ refer to the first domains of the $\alpha$ and $\beta$ chains, while $\alpha 2$ and $\beta 2$ refer to the second domains. S-S represents a disulphide bond

\section{Detection of MHC polymorphism}

\section{Serological and cellular typing}

Serological typing was the first method to detect MHC polymorphism. Antibodies which recognise epitopes characteristic of particular MHC-encoded molecules have defined the class I gene polymorphisms A1-Aw74, Bw4-Bw77 and Cw1-Cw11 [10]. Polymorphism also occurs at the class II loci. The DRB1 and DRB3/DRB4 genes (Fig. 1) encode distinct $\beta$-chains. These combine with an $\alpha$-chain encoded by the non-polymorphic DRA gene to produce distinct DR molecules. DRB1 polymorphisms produce the serological specificities DR1DRw18, while DRB3 polymorphisms are distinguished by the DRw52a-c specificities [10]. Some haplotypes carry a DRB4 gene instead of the DRB3 gene. This encodes a $\beta$ chain producing the DRw53 specificity [11]. DQ and DP polymorphisms have also been distinguished serologically [12].

Cellular typing [13], using the mixed lymphocyte reaction, also defines class II polymorphism. This technique is considered a 'functional' analysis since it depends on Tcell activation to distinguish the specificities Dw1-26. It is not always clear, however, whether the polymorphism detected is determined by variation at the $\mathrm{DR}$ and/or DQ loci, or even at an unmapped 'Dw' locus. Another cellular different DR haplotypes. The diagram is not to scale and certain genes have been omitted. (For more detailed maps of this region see $[5,6])$

method, primed lymphocyte typing, has distinguished polymorphism at the DP loci [13].

Although the above techniques have generated much data, they are limited by the antisera and T-cell clones available. For example, individuals homozygous for a particular allele cannot be distinguished from those heterozygous for that allele and a 'blank' allele. (A 'blank' allele produces a specificity unrecognised by any available typing reagent). This hinders investigation of inheritance of disease susceptibility [14]. These methods, moreover, do not show whether the detected polymorphism occurs in the $\alpha$ - or the $\beta$-chain of the DQ molecule. Finally, subtypes of class II molecules which possess a common epitope may be recognised as one specificity only by available antisera.

\section{Recombinant DNA technology}

Recombinant DNA technology has enabled investigation of class II gene polymorphism at the DNA level. The main techniques used are restriction fragment length polymorphism (RFLP) analysis, DNA sequencing and allele-specific oligonucleotide (ASO) dot blot analysis.

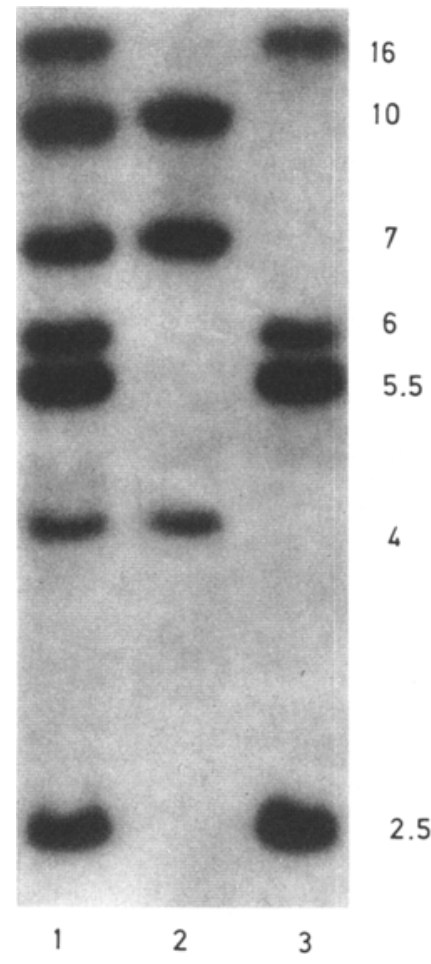

Fig.3. Autoradiograph of RFLPs obtained by digesting genomic DNA with Taq I and hybridising the fragments with a DRB gene probe. Numbers on the vertical axis are fragment sizes measured in kilobases (kb). Each column shows DNA from a Type 1 diabetic subject. Column 2 shows a $10+7+4 \mathbf{k b}$ pattern typical of a DR3 homozygote. Column 3 shows a $16+6+5.5+2.5$ pattern typical of a DR4 homozygote. Column 1 shows both patterns combined in a DR3/4 heterozygote 
Genomic DNA

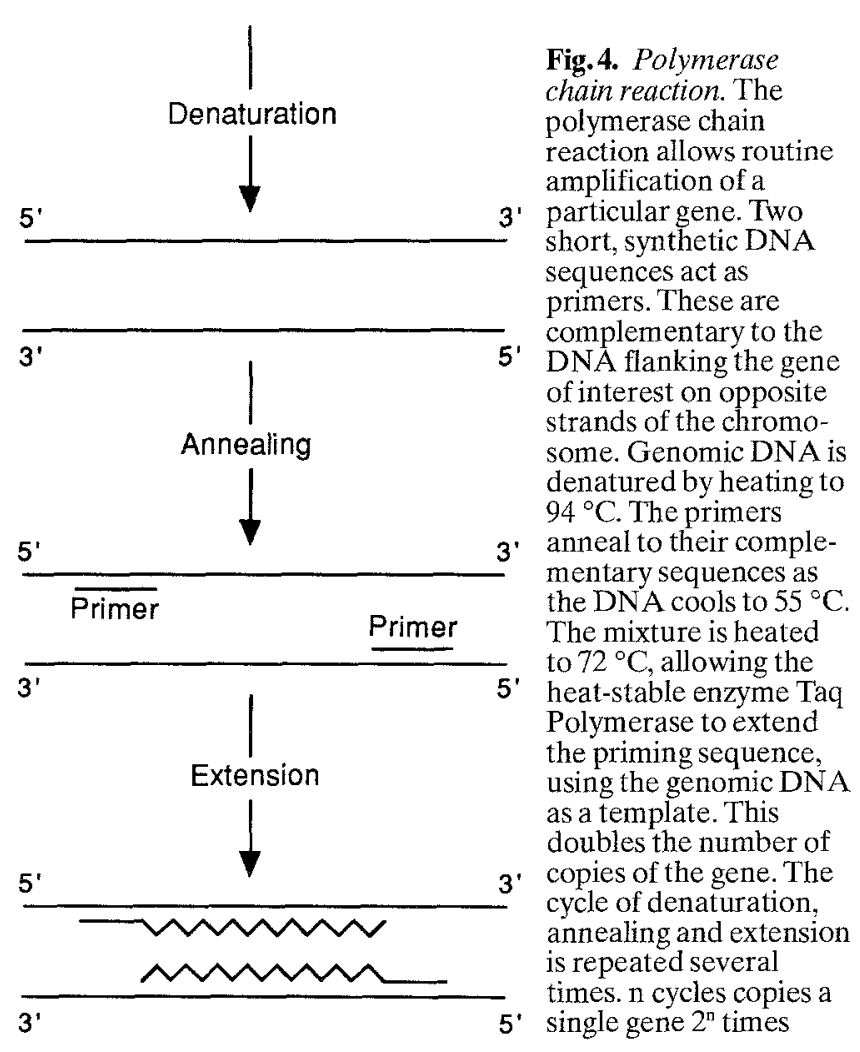

RFLP analysis uses restriction enzmyes which cut genomic DNA (extracted from peripheral blood lymphocytes) at specific nucleotide sequences. Gene polymorphisms involving such sequences alter the sizes of the resulting DNA fragments. These fragments are separated by electrophoresis on an agarose gel. The DNA is rendered single-stranded and blotted onto nylon filters by the method of Southern [15]. Radiolabelled DNA containing a sequence of interest (a gene probe) is added to the filter. This hybridises to complementary DNA fragments which are visualised by autoradiography. Polymorphisms of class II genes are recognised as characteristic patterns (RFLPs) of DNA fragments (Fig.3).

All alleles produce an RFLP, and therefore no polymorphism will be missed as a 'blank'. RFLP analysis does, however, have certain limitations. Much polymorphism occurs in non-coding DNA surrounding the gene (flanking sequences) and within it (introns). Such polymorphism is not always associated with variation in coding sequences. Polymorphism in sequences encoding the functionally important first domains of the class II $\alpha$ - and $\beta$-chains may, moreover, be missed with the commonly used restriction enzymes.
The most accurate method of defining gene polymorphism is DNA sequencing of the different alleles. This lengthy procedure is impractical for population studies. In large studies, short DNA sequences within the first domain-coding regions of known class II $A$ and $B$ alleles which are unique to each allele have been identified. Hybridisation of genomic DNA to a short (oligonucleotide) radiolabelled DNA probe which contains the unique sequence demonstrates the presence or absence of that allele. The sensitivity and specificity of this method are increased by producing several million copies of the investigated gene, using the polymerase chain reaction (PCR, Fig.4). DNA amplified by this method [16] is dotted onto a nylon filter and hybridised with a radiolabelled allelespecific oligonucleotide (ASO) which detects the allele of interest. The filter is washed to remove non-specifically bound probe. Autoradiography shows DNA containing the allele of interest as a dot (Fig. 5).

These techniques have defined the DQA1 alleles A1A4 [17], the DQB1 alleles w1-w9 [10, 18], subdivisions of some serologically defined DR alleles [18], and a range of DP alleles [19].

\section{Linkage disequilibrium in disease association studies}

Certain combinations of alleles at different MHC loci are inherited at frequencies greater than would be expected by chance. This phenomenon is termed linkage disequilibrium. An MHC allele may, therefore, be secondarily associated with Type 1 diabetes because of linkage disequilibrium with an allele at another locus which encodes a disease susceptibility determinant. Allelic associations with Type 1 diabetes do not, therefore, imply a direct effect of that allele on disease predisposition.

Serological typing in Caucasian subjects demonstrated the positive association between the MHC class I antigen B15 and Type 1 diabetes [20]. Subsequent reports showed an additional positive association with $\mathrm{B} 8$, and a negative association with $\mathrm{B} 7[21,22]$.

Cellular typing showed positive associations between Dw3 and Dw4 and Type 1 diabetes [23]. Serological DRtyping has demonstrated positive associations with DR3 and DR4, and a negative association between the disease and DR2 [24, 25].

MHC class II associations with Type 1 diabetes are consistently stronger than the class I associations. Class I associations are secondary to the class II associations [26], because of linkage disequilibrium between the class I and class II loci. In Caucasians, DR3 is in linkage disequilibrium with B8, DR4 with B15, and DR2 with B7 [12].

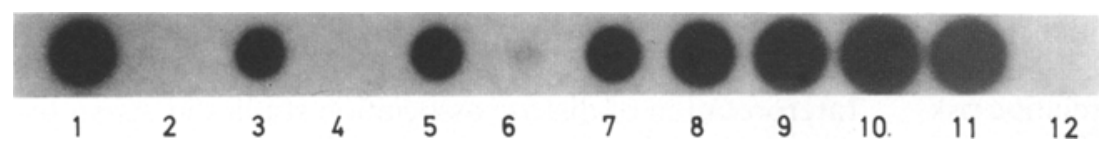

Fig.5. Autoradiograph of amplified DNA from 12 Type 1 (insulindependent) diabetic subjects. The DNA has been amplified for the DQA1 gene and probed with a radiolabelled ASO specific for the

A3 allele. Subjects 1, 3, 5, and 7-11 possess the allele, while subjects $2,4,6$ and 12 do not 
Class I alleles are therefore unlikely to determine diabetes susceptibility directly, and their associations with disease will not be considered further.

Although the positive associations between Type 1 diabetes and DR3 and DR4 are strong (one or both are found in more than $95 \%$ of Caucasian Type 1 diabetic subjects), these antigens also occur in up to $60 \%$ of the healthy Caucasian population [25]. Regardless of their penetrance, DR3 and DR4 are too frequent in healthy subjects to explain the observed prevalence of the disease, assuming that these antigens predispose directly to diabetes [27]. It appears therefore that the DR associations with Type 1 diabetes are also secondary to linkage disequilibrium between the DRB1 locus and diabetes susceptibility gene(s).

The strong DR associations with Type 1 diabetes suggest that diabetes susceptibility loci lie near the DRB1 gene, probably within the class II region. Polymorphism occurs at both the DP and DQ loci. In the single study of Caucasian Type 1 diabetic subjects using primed lymphocyte typing, no DP allele was significantly associated with the disease [28]. Interest has therefore focussed on the DQ loci.

The DQ loci consist of the DQA1, DQA2, DQB1 and DQB2 genes (Fig.1). The DQA2 and DQB2 genes may be non-functional [29]. Linkage disequilibrium between the DRB1, DQA1 and DQB1 loci is extremely strong [30], suggesting that recombination between DR and DQ is rare. Linkage analysis of class II-associated diabetes susceptibility is, therefore, impractical since the chance of observing a recombination event between $\mathrm{DR}$ and $\mathrm{DQ}$ in a multiplex diabetic family is very small. Affected siblingpair studies have been important, however, in confirming linkage of diabetes susceptibility with the MHC [24].

\section{Trans-racial studies}

An alternative method of mapping disease susceptibility has come from the study of disease associations in different races. Although linkage disequilibrium is strong within the class II region, recombination events during evolution have generated combinations of MHC alleles (extended haplotypes) which vary in frequency between populations $[12,31]$. This has caused disease-predisposing alleles within the MHC to be in linkage disequilibrium with different marker alleles in different races. Any allele which is consistently associated with a disease in all races, irrespective of the extended haplotype on which it occurs, is likely to determine disease susceptibility [32-34]. Such studies assume that the disease in question has the same genetic basis in all races. Trans-racial studies therefore require rigorous application of diagnostic criteria for disease, and careful matching of disease and control populations for ethnic origin. The observed frequencies of diseased individuals are used to construct $2 \times 2$ tables. From these the odds ratio (an estimate of the relative risk of developing the disease conferred by an allele) can be deduced. The statistical significance of this risk can also be calculated [35]. Inadequate racial matching may produce spurious associations due to ethnic stratification. Studies of small populations may obscure true associations [36].

\section{DR associations with Type 1 diabetes in different races}

The majority of disease association studies have used serological and cellular methods. These are reviewed briefly.

\section{White Caucasians}

Studies in Caucasians have confirmed the positive associations between DR3 and DR4 and Type 1 diabetes, and the negative association with DR2. Rank order analysis has shown that in the absence of DR3 and DR4, most DR antigens have an effect on diabetes susceptibility [37]. This may be due to differences in linkage disequilibrium between a small number of diabetes susceptibility alleles and the various DRB1 alleles, or to each DRB1 allele being linked to a distinct allele at a single disease susceptibility locus, each with a unique effect on disease predisposition. Alternatively, different DR types may be linked with alleles at various susceptibility loci.

In this race DR3 and DR4 have a synergistic effect on disease predisposition. For example, Wolf et al. observed 62 DR3/4 heterozygotes out of 122 Type 1 diabetic subjects, significantly more than the 39 expected from the gene frequencies of DR3 and DR4 $(P<0.001)$. The relative risk of Type 1 diabetes amongst DR3/4 heterozygotes was 14.3 compared with 5 for DR3 alone and 6.8 for DR4 alone [25]. The frequencies of DR3 and DR4 amongst diabetic subjects can be explained by a DR3linked gene acting recessively in the absence of DR4, and a DR4-linked gene acting dominantly in the absence of DR3 [14]. DR3- and DR4-related disease-susceptibility factors, therefore, are distinct.

\section{Negroid subjects}

Studies in negroid populations have demonstrated a positive association between Type 1 diabetes and DR4 in this race $[33,38-40]$. DR3 is significantly associated with the disease in some studies [38,39], but not in others [33, 4042]. Combined analysis has shown an overall significant positive association with DR3 [33]. Combined analysis also demonstrated a significant positive association between both DR7 and DR9 and Type 1 diabetes [33]. The association with DR7 appears specific to the negroid race. DR2 is significantly negatively associated with the disease in this race.

\section{Asian Indians}

Interpretation of disease association studies in Asian Indians is complicated by their ethnic heterogeneity. Nevertheless, the consensus of reported studies indicates that Type 1 diabetes is positively associated with both DR3 
and DR4 [43-45]. The association with DR3 appeared stronger in this race. DR2 was not significantly associated with the disease.

\section{Chinese}

Published studies have shown a consistent positive association between DR3 and Type 1 diabetes [46-50]. In contrast with other races, a significant positive association between DR4 and disease was not found. DR9 was significantly positively associated with Type 1 diabetes in one study [47]. Synergism between DR3 and DR9 and disease susceptibility was found in Hong Kong Chinese [49]. The negative association between DR2 and disease was not significant in any study.

\section{Japanese}

Type 1 diabetes was positively associated with DR4 and negatively associated with DR2 [51-54]. DR9 was also significantly positively associated with disease in some studies $[53,54]$. The rarity of DR3 in this race is noteworthy [54]. The absence of a DR3-associated diseasepredisposing allele on DR3 haplotypes from this race may partly explain the low incidence of Type 1 diabetes in the Japanese population.

These data are summarised in Table 1. They indicate that the disease-predisposing effects of the DRB1 alleles (with the exception of DR3) are not consistent in all races. This implies that alleles of the DRB1 gene do not determine disease susceptibility, but that they are in linkage disequilibrium with other susceptibility alleles. Alternatively, heterogeneity within the DR specificities may obscure disease associations with certain DR subtypes. Genetic markers which are consistently associated with Type 1 diabetes in all races have, therefore, been sought.

\section{The search for specific markers of disease susceptibility}

\section{DR4-associated disease predisposition}

The search for DQ alleles associated with Type 1 diabetes was initiated by the discovery of a DRB-related RFLP which distinguished two subsets of Caucasian DR4 haplotypes [55]. One was significantly positively associated with Type 1 diabetes. The RFLP corresponded to a subset of the serological specificity DQw3 [56]. Caucasian DR4 haplotypes possess a DQB1 allele encoding either the DQw3.1 (now termed DQw7) specificity or the DQw3.2 specificity (now termed DQw8). Some $90 \%$ of Caucasian DR4-positive Type 1 diabetic patients possess the DQw8 allele, compared with some $50 \%$ of racially-matched DR4-positive control subjects [57]. This suggested that DR4-associated susceptibility to diabetes is determined by the DQw8 allele. In support of this, a DQB RFLP corresponding to DQw8 marked a subset of DR4-positive North Indian Asians at increased risk of the disease [45].
Data from a Japanese population, however, contradict this hypothesis. Serological DQ-typing has shown that DR4 haplotypes are associated with one of three DQB1 alleles in this race: DQw7, DQw8 and DQw4. In Japanese Type 1 diabetic subjects, DQw4 is significantly associated with disease, while DQw8 is not [54]. This has been confirmed by ASO dot blot analysis [58].

DQw8 is not associated with Type 1 diabetes in all races and is, therefore, unlikely to be a primary disease susceptibility determinant. This is supported by other data. Cellular typing and DNA sequence analysis divide DR4 into at least five subtypes: Dw4, Dw10, Dw13, Dw14 and Dw15. In Caucasians, only the Dw4 and Dw10 subtypes in combination with DQw8 were significantly associated with Type 1 diabetes [59]. Analysis of other data [60] confirms this. A combination of Dw4/Dw10 and DQw8 may, therefore, determine disease susceptibility, or an allele at another locus on the DR4(Dw4/Dw10)-DQw8 haplotypes may encode predisposition to diabetes.

The identity of such a gene has been suggested by trans-racial gene mapping. Although DR7 is not associated with Type 1 diabetes in Caucasians [37], it is positively associated with the disease in negroid populations [33]. A DQB RFLP identified a subset of DR7-positive negroid haplotypes which was strongly associated with disease [33]. The first domain-coding portions of the DRB1, DQA1 and DQB1 genes of this DR7 haplotype were sequenced. The sequences were compared with those of the Caucasian DR7 haplotype [34]. The DRB1 and DQB1 alleles of the two haplotypes were identical, but the DQA1 alleles were different (Table 2). While the Caucasian DR7 haplotype possessed the A2 allele [17], the negroid DR7 haplotype possessed the A3 allele characteristic of Caucasian DR4 haplotypes [17]. The A3 allele was significantly positively associated with Type 1 diabetes in a negroid population [34], and in a Japanese population [58]. This association also occurred in Caucasians [60]. Unpublished data from our unit showed a significant association between $\mathrm{A} 3$ and the disease in North

Table 1. DR/DQ associations with Type 1 (insulin-dependent) diabetes in different races

\begin{tabular}{|c|c|c|c|c|c|c|}
\hline Gene & Allele & $\begin{array}{l}\text { Cauca- } \\
\text { sian }\end{array}$ & $\begin{array}{l}\text { Asian } \\
\text { Indian }\end{array}$ & Chinese & Negroid & $\begin{array}{l}\text { Japa- } \\
\text { nese }\end{array}$ \\
\hline$\overline{\text { DRB1 }}$ & $\begin{array}{l}\text { DR2 } \\
\text { DR3 } \\
\text { DR4 } \\
\text { DR7 } \\
\text { DR9 }\end{array}$ & $\begin{array}{l}- \\
+ \\
+ \\
\mathrm{N} \\
\mathrm{N}\end{array}$ & $\begin{array}{l}\text { N/- } \\
+ \\
+ \\
- \\
?\end{array}$ & $\begin{array}{l}\mathrm{N} /- \\
+ \\
\mathrm{N} /+ \\
? \\
\mathrm{~N} /+\end{array}$ & $\begin{array}{l}- \\
+ \\
+ \\
+ \\
+\end{array}$ & $\begin{array}{l}\mathrm{r} \\
\mathrm{r} \\
\mathrm{r} \\
+\end{array}$ \\
\hline DQB1 & $\begin{array}{l}\text { DQw2 } \\
\text { DQw6/1.18 }\end{array}$ & + & + & $?$ & $\begin{array}{l}+ \\
-\end{array}$ & r \\
\hline DQA1 & A3 & + & + & $?$ & + & + \\
\hline
\end{tabular}

+ represents a consistent positive association between Type 1 diabetes and the allele. - represents a negative association. $\mathrm{N}$ represents a neutral association. $\mathrm{N} /+$ and $\mathrm{N} /$ - indicate nonsignificant trends towards positive or negative associations. $r$ indicates that an allele is too rare to assess its association with the disease. ? indicates that data are insufficient to assess the association between the allele and Type 1 diabetes in that group. Associations are quoted from studies cited in the text 
Table 2. Associations between Type 1 (insulin-dependent) diabetes and DR7, and DR9-bearing class II haplotypes in Caucasian and Negroid populations

\begin{tabular}{lllll}
\hline \multicolumn{2}{l}{ Class II allele } & & & \\
\hline DQB1 & DQA1 & DRB1 & Race & Association \\
\hline DQw2 & DQA2 & DR7 & Caucasian & Neutral \\
DQw2 & DQA3 & DR7 & Negroid & Positive \\
DQw9 & DQA3 & DR9 & Caucasian & Neutral \\
DQw2 & DQA3 & DR9 & Negroid & Positive \\
\hline
\end{tabular}

Indian subjects. This consistent association (Table 1) indicates that $\mathrm{A} 3$ might be primarily associated with Type 1 diabetes. If so, another locus on the DR4 haplotype must also affect disease susceptibility since $\mathrm{A} 3$ does not distinguish between DR4-positive diabetic subjects and DR4positive healthy control subjects [60].

Although DR4 is common in the Chinese race, it is not significantly associated with diabetes. If the A3 allele is significantly associated with disease in this race, its effect would be independent of DR4, supporting A3 as a primary determinant of disease susceptibility. This hypothesis should, therefore, be tested by investigating MHC class II associations with diabetes in the Chinese race.

\section{Disease markers which protect against Type 1 diabetes}

A negative association between DR2 and diabetes has been found in most races. DR2 does not directly protect against Type 1 diabetes, however, since this association is weak in Asian Indian and Chinese populations. It is likely that the DRB1 allele encoding DR2 is in linkage disequilibrium with a protective allele. A DQB RFLP associated with subgroups of DR2, DR5 and DRw6 in Caucasians, negroid individuals and Asian Indians $[33,45]$ was negatively associated with Type 1 diabetes. This RFLP characterises the DQB1 alleles DQw6 (previously termed DQw1.2) on DR2 haplotypes [61], and DQw1.18 on DRw6 haplotypes [30]. The first domain-coding sequences of these alleles are almost identical, differing at only one codon [18]. The DQw6 allele is also negatively associated with Type 1 diabetes in the Japanese race (Table 2, [54]). DQw1.18 and DQw6, therefore, may directly protect against Type 1 diabetes. Detection of a significant negative association between the disease and DQw6/DQw1.18 in the Chinese race would support the hypothesis that an MHC 'protective' gene exists within the DQ sub-region.

\section{DR3-associated susceptibility to Type 1 diabetes}

Variation in DR3 haplotypes was associated with differences in susceptibility to Type 1 diabetes [62], suggesting that the DRB1 allele does not predispose to disease directly. DR3 is associated with the DQB1 allele DQw2 in most races, but in negroid populations DR3 is associated with either DQw2 or DQw4 [63]. The DR3-DQw4 haplotype is not associated with diabetes, suggesting that DQw2 may predispose to disease directly, while DQw4 is protective [63]. DQw2 and DQw4, however, are associated with different subtypes of the DRB1 allele [64]. The two DR3 haplotypes also possess slightly different DQA 1 alleles. It is conceivable that any of these (or other) haplotypic differences could account for their differing susceptibilities to diabetes.

The DQw2 allele also occurs on the diabetes-predisposing negroid DR9 haplotype [34], while the non-predisposing Caucasian DR9 haplotype possesses the DQw9 allele (Table 2). While the DQw2 allele may account for the difference in disease susceptibility between these DR 9 haplotypes, DR9 in the Japanese is associated with the same DR/DQ alleles as DR9 in Caucasians [58]. If allocation of these class II sequences to the Japanese DR9 haplotype is confirmed, one may deduce that DQw2 does not determine DR9-associated susceptibility to Type 1 diabetes. No convincing data exist, therefore, to implicate DQw2 as the allele on the DR3 haplotype most likely to determine disease susceptibility, in spite of its consistent association with diabetes (Table 1).

\section{Position 57 of the $D Q \beta$ chain in disease susceptibility}

The above findings indicate that alleles at the DQA1 and DQB1 loci are better markers than the DRB1 alleles for some MHC associations with Type 1 diabetes. This has stimulated the search for structural features of the DQ molecule which might directly affect predisposition to disease. Todd et al. [18] have sequenced the DRB, DQA1 and DQB1 alleles of several Caucasian haplotypes. Haplotypic predisposition to diabetes correlated with the codon for the amino acid at position 57 on the DQ $\beta$ chain. Aspartate at this position (Asp 57) correlated negatively with Type 1 diabetes, while non-Asp 57-encoding alleles were positively associated with disease. (The Caucasian DR7 haplotype did not fit this correlation, but alteration of disease susceptibility by the DR7-associated DQA1 allele provided a possible explanation). It was proposed that the amino acid at position 57 might be critical in determining disease susceptibility. Support for this hypothesis has come from a family study which examined linkage of nonAsp $57 \mathrm{DQB}$ alleles with inheritance of diabetes [65].

The above hypothesis is attractive and has generated much interest. It fails, however, to explain the synergistic effect of DR3 and DR4 on diabetes susceptibility seen in Caucasian populations. This indicates that the DR3m and DR4-associated susceptibility factors are distinct. It is therefore unlikely that the same amino acid encoded by the DQB1 genes on the DR3 and DR4 haplotypes could explain both DR3- and DR4-associated disease susceptibility.

A second objection is that different MHC haplotypes show a gradation of disease susceptibility [37]. Susceptibility to disease is, therefore, not an all-or-none phenomenon due to the presence or absence of Asp 57 on the DQ $\beta$ chain. As stated previously [18], modification by the DQ $\alpha$-chain may explain some of the inconsistencies, but other objections remain. 
In non-Caucasoid races the correlation between Asp 57 and Type 1 diabetes is less convincing. Non-Asp 57 homozygosity was non-significantly associated with diabetes in the Chinese race [66]. The disease is positively associated with the Asp 57-positive DQ 3 -chains DQw4 and DQw9 in the Japanese race, however, while the nonAsp 57 DQw8 is not associated with diabetes $[54,58]$. These data imply that if the amino acid at position 57 is involved in disease susceptibility, one or more other MHCassociated factors must be equally, if not more important.

\section{Other possible determinants of disease susceptibility}

DQA1 and DQB1 alleles do not, therefore, explain all the observed MHC class II associations with Type 1 diabetes. A DQA2 RFLP was associated with diabetes in DR3positive subjects [67], but the association was not found in the Chinese race [50]. This indicates that the association in Caucasians was due to linkage disequilibrium between the DQA2 polymorphism and a disease-susceptibility allele at a different locus.

Tumour necrosis factor- $\alpha$ (TNF- $\alpha$ ) potentiates the toxic effect of interleukin- 1 on the pancreatic Beta-cell in vitro [68]. Since the TNF- $\alpha$ gene exists within the MHC (Fig. 1), gene polymorphism might alter TNF- $\alpha$ secretion or action, and hence affect susceptibility to diabetes. RFLP analysis found only two polymorphisms of the TNF- $\alpha$ gene [69]. In Caucasian subjects heterozygosity for this polymorphism was significantly associated with Type 1 diabetes [69]. This could be explained by the association of one polymorphism with the Caucasian DR4 haplotype, and of the others with the B8-DR3 haplotype. TNF- $\alpha$ heterozygosity may, therefore, have reflected DR3/4 heterozygosity rather than a direct effect on disease susceptibility. These observations, therefore, require repetition in large populations from different ethnic groups, prior to further speculation concerning TNF- $\alpha$ polymorphism in susceptibility to diabetes.

The discovery of other genes within the MHC suggests further candidate susceptibility loci. If such genes are both functional and transcribed, further disease association studies in a variety of ethnic groups may be used to assess their contribution to disease susceptibility.

\section{Conclusions}

The genetic basis for susceptibility to Type 1 diabetes is unclear, although the DQ loci are strongly implicated. Models of disease where one gene allele is associated with susceptibility, while another is not are probably too simple. The DQ gene products form a single molecule. DQ function is likely to be determined by its overall structure. If DQ polymorphism is important in disease predisposition, specific combinations of DQA1 and DQB1 allele products will result in molecular structures that alter the process of islet Beta-cell destruction. Observations in man [70] and a murine model of Type 1 diabetes [71] have indicated that the disease is caused by a T-cell dependent process. Certain DQ structures may, therefore, present antigens critical to Beta-cell destruction to either exacerbate or damp down that process. Alternatively, since class II molecules restrict T-cell repertoire [72], DQ polymorphisms may delete clones of T-cells so that Betacell antigens are not recognised, thus protecting against diabetes. The paucity of knowledge concerning the pathogenesis of this disease makes such suggestions speculative. It should be noted, however, that when allelic associations with disease are found, their possible function in diabetes pathogenesis must be considered. Increased understanding of the pathogenesis of autoimmunity will facilitate this.

The available data implicate a DQA1 allele in DR4associated predisposition to Type 1 diabetes, while two very similar DQB1 alleles may confer protection. At least one other MHC gene appears responsible for DR3-associated disease susceptibility. The involvement of non-MHC genes and environmental factors indicates that Type 1 diabetes is a disease of considerable complexity. Although MHC alleles at several loci on an extended haplotype may contribute to disease predisposition [73], such an hypothesis requires the construction of complex models of disease. Such models cannot be rejected with the available data. Further progress will come from testing simple models involving one or two genes in large, well-characterised populations with tightly matched control groups. Transracial comparisons are a powerful test of any disease associations which may be found. Consistent associations can be incorporated into more complex models of disease. Formal identification of alleles as susceptibility determinants will require identification of the gene products as determinants of insulitis. Progress in the genetics of Type 1 diabetes will, therefore, increase understanding of its pathogenesis.

Acknowledgements. We thank Dr. J. Todd for useful discussion. DJ is supported by Eli Lilly (UK), CM by the Wellcome Trust, KHJ by the Medical Research Council. We are grateful for additional financial support from the Wellcome Trust, the British Diabetic Association, the Medical Research Council, Nordisk (UK) and Eli Lilly (UK).

\section{References}

1. Rotter JI, Landaw EM (1984) Measuring the genetic contribution of a single locus to a multilocus disease. Clin Genet 26:529542

2. Field LL (1988) Insulin-dependent diabetes mellitus: a model for the study of multifactorial disorders. Am J Hum Genet 43: 793798

3. Carroll MC, Belt KT, Palsdottir A, Yu Y (1985) Molecular genetics of the fourth component of human complement and steroid21-hydroxylase. Immunol Rev 87:39-60

4. Spies T, Morton CC, Nedospasov SA, Fiers W, Pious D, Strominger JL (1986) Genes for the tumour necrosis factors $\alpha$ and $\beta$ are linked to the human major histocompatibility complex. Proc Natl Acad Sci USA 83: 8699-8702

5. Sargent CA, Dunham I, Trowsdale J, Campbell RD (1989) Human major histocompatibility complex contains genes for the major heat shock protein HSP 70. Proc Natl Acad Sci USA 86: 1968-1972

6. Sargent CA, Dunham I, Campbell RD (1989) Identification of multiple H'TF-island associated genes in the human major histocompatibility complex class III region. EMBO 8: 2305-2312 
7. Schwartz RH (1985) T-lymphocyte recognition of antigen in association with gene products of the major histocompatibility complex. Ann Rev Immunol 3: 237-261

8. Campbell RD (1987) The molecular genetics and polymorphism of C2 and factor B. Br Med Bull 43: 37-49

9. Carroll MC, Alper CA (1987) Polymorphism and molecular genetics of human C4. Br Med Bull 43: 50-65

10. Nomenclature for factors of the HLA system (1987) Tissue Antigens 32: 117-187

11. Gorski J, Rollini P, Mach B (1987) Structural comparison of the genes of two HLA-DR supertypic groups: the loci encoding DRw52 and DRw53 are not truly allelic. Immunogenetics 25 : 397-402

12. Bodmer JG, Kennedy LJ, Lindsay J, Wasik AM (1987) Applications of serology and the ethnic distribution of three locus HLA haplotypes. Br Med Bull 43: 94-121

13. Festenstein H, Ollier W (1987) Cellular typing and functional heterogeneity of MHC-encoded products. Br Med Bull 43: 122155

14. Louis EJ, Thomson G (1986) Three-allele synergistic mixed model for insulin-dependent diabetes. Diabetes 35: 958-963

15. Southern EM (1975) Detection of specific sequences among DNA fragments separated by gel electrophoresis. J Mol Biol 98: 503-517

16. Saiki RK, Bugawan TL, Horn GT, Mullis KB, Erlich HA (1986) Analysis of enzymatically amplified $\beta$-globin and HLA-DQ $\alpha$ DNA with allele-specific oligonucleotide probes. Nature 324: 163-166

17. Gyllensten UB, Erlich HA (1988) Generation of single-stranded DNA by the polymerase chain reaction and its application to direct sequencing of the HLA-DQA locus. Proc Natl Acad Sci USA 85: 7652-7655

18. Todd JA, Bell JI, McDevitt HO (1987) HLA-DQß gene contributes to susceptibility and resistance to insulin-dependent diabetes mellitus. Nature 329:599-604

19. Bugawan TL, Horn GT, Long CM, Mickelson E, Hansen JA, Ferrara GB, Angelini G, Erlich HA (1988) Analysis of HLADP allelic polymorphism using the in vitro enzymatic DNA amplification of DP- $\alpha$ and DP- $\beta$ loci. J Immunol 141: 4024-4030

20. Singal DP, Blajchman MA (1973) Histocompatibility (HL-A) antigens, lymphocytotoxic antibodies and tissue-specific antibodies in patients with diabetes mellitus. Diabetes 22: 429-432

21. Nerup J, Platz P, Andersen OO, Christy M, Lyngsoe J, Poulsen JE, Ryder LP, Nielsen LP, Thomsen M, Svejgaard A (1974) HL-A antigens in diabetes mellitus. Lancet II: 864-866

22. Cudworth AG, Woodrow JC (1975) HLA system and diabetes mellitus. Diabetes 24:345-349

23. Svejgaard A, Platz P, Ryder LP, Nielsen LS, Thomsen M (1975) HL-A and disease associations - a survey. Transplant Rev 22: 343

24. Svejgaard A, Platz P, Ryder LP (1980) Joint report: insulin-dependent diabetes mellitus. In: Terasaki PI (ed) Histocompatibility testing. UCLA, Tissue Typing Laboratory, California, pp 638-656

25. Wolf E, Spencer KM, Cudworth AG (1983) The genetic susceptibility to Type 1 (insulin-dependent) diabetes: analysis of the HLA-DR association. Diabetologia 24: 224-230

26. Platz P, Jakobsen BK, Morling N, Ryder LP, Svejgaard A, Thomsen M, Christy M, Kromann H, Benn J, Nerup J, Green A, Hauge M (1981) HLA-D and -DR antigens in genetic analysis of insulin-dependent diabetes mellitus. Diabetologia 21: $108-115$

27. Thomson G (1984) HLA DR antigens and susceptibility to insulin-dependent diabetes mellitus. Am J Hum Genet 36: 13091317

28. Jongh BM de, Termijtelen A, Bruining GJ, Vries RRP de, Rood JJ van (1984) Relation of insulin-dependent diabetes mellitus (IDD) and the HLA-linked SB system. Tissue Antigens 23: $87-93$

29. Trowsdale J (1987) Genetics and polymorphism: class II antigens. Br Med Bull 43: 15-36
30. Serjeantson SW, Kohonen-Corish MRJ, Dunckley H, Reid MA (1986) HLA class II RFLPs are haplotype-specific, Cold Spring Harbour Symp Quant Biol 51: 83-89

31. Baur MP, Neugebauer M, Albert ED (1984) Reference tables of two-locus haplotype frequencies for all MHC marker loci. In: Albert ED, Baur MP, Mayr WR (eds) Histocompatibility. Springer, Berlin Heidelberg New York, pp 677-755

32. Bodmer WF, Thomson G (1977) Population genetics and evolution of the HLA system. In: Dausset J, Svejgaard A (eds) HLA and disease. Munksgaard, Copenhagen, pp 280-295

33. Fletcher J, Mijovic C, Odugbesan O, Jenkins D, Bradwell AR, Barnett AH (1988) Trans-racial studies implicate HLA-DQ as a component of genetic susceptibility to Type 1 (insulin-dependent) diabetes. Diabetologia 31: 864-870

34. Todd JA, Mijovic C, Fletcher J, Jenkins D, Bradwell AR, Barnett AH (1989) Identification of susceptibility loci for insulin-dependent diabetes mellitus by trans-racial gene mapping. Nature 338: 587-589

35. Mathews JD (1984) Statistical aspects of immunogenetic associations with disease. In: Simons MJ, Tait BD (eds) Detection of immune-associated genetic markers of human disease. Churchill Livingstone, London, pp 106-136

36. Cox NJ, Bell GI (1989) Disease associations: chance, artifact, or susceptibility genes? Diabetes 38: 947-950

37. Thomson G, Robinson WP, Kuhner MK, Joe S, MacDonald MJ Gottschall JL, Barbosa J, Rich SS, Bertrams J, Baur MP, Partanen J, Tait BD, Schober E, Mayr WR, Ludvigsson J, Lindblom B, Farid NR, Thompson C, Deschamps I (1988) Genetic heterogeneity, modes of inheritance, and risk estimates for a joint study of Caucasians with insulin-dependent diabetes mellitus. Am J Hum Genet 43: 799-816

38. Ottenhoff THM, Mengistu M, Tadesse G, Vries RRP de, Converse PJ (1987) HLA-DR and DQ antigens in insulin-dependent diabetics in Ethiopia. Tissue Antigens 30: 193-197

39. Reitnauer PJ, Roseman JM, Barger BO, Murphy CC, Kirk KA, Acton RT (1981) HLA associations with insulin-dependent diabetes mellitus in a sample of the American black population. Tissue Antigens 17: 286-293

40. Omar MAK, Hammond MG, Asmal MC (1984) HLA-A, B, C and DR antigens in young South African blacks with Type 1 (insulin-dependent) diabetes mellitus. Diabetologia 26: 20-23

41. Orren A, Taljaard D, Du Toit E (1985) HLA-A, B, C and DR antigen associations in insulin-dependent diabetes mellitus (IDDM) in South African negro (black) and Cape coloured people. Tissue Antigens 26: 332-339

42. MacDonald MJ, Famiyuwa OO, Nawabuebo IA, Bella AF, Junaid TA, Marrari M, Duquesnoy RJ (1986) HLA-DR associations in black Type 1 diabetics in Nigeria: further support for models of inheritance. Diabetes 35: 583-589

43. Serjeantson SW, Ranford PR, Kirk RL, Kohonen-Corish MRJ, Mohan V, Ramachandran A, Snehalatha C, Viswanathan M (1987) HLA-DR and DQ DNA genotyping in insulin-dependent diabetes patients in South India. Disease Markers 5: 101-108

44. Bhatia E, Mehra NK, Taneja V, Vaiya MC, Ahuja MM (1985) HLA-DR antigen frequencies in a North Indian Type 1 diabetic population. Diabetes 34: 565-567

45. Fletcher J, Odugbesan O, Mijovic C, Mackay E, Bradwell AR, Barnett AH (1988) Class II HLA DNA polymorphisms in Type 1 (insulin-dependent) diabetic patients of North Indian origin. Diabetologia 31:343-350

46. Maeda H, Takeuchi F, Juji T, Akanuma Y, Kasuga M, Lee YS, Kosaka K, Tsai SH (1980) HLA-DRw3 in juvenile onset diabetes mellitus in Chinese. Tissue Antigens 15: 173-176

47. Fan L, Xu J, Ding H, Fei H, Chen R, Yu H (1984) HLA and in sulin-dependent diabetes mellitus. Chinese Med J 97: 371-375

48. Chan SH, Yeo PPB, Lee BW, Tan SH, Cheah JS, Wong HB (1985) HLA and insulin-dependent diabetes mellitus in Singaporean Chinese. Ann Acad Med Singapore 14: 215-218

49. Hawkins BR, Lam KSL, Ma JTC, Low LCK, Cheung PT, Serjeantson SW, Yeung RTT (1987) Strong association of HLA- 
DR3/DRw9 heterozygosity with early-onset insulin-dependent diabetes mellitus in Chinese. Diabetes 36:1297-1300

50. Kohonen-Corish MRJ, Serjeantson SW, Lee HK, Zimmet P (1987) Insulin-dependent diabetes mellitus: HLA-DR and -DQ typing in three ethnic groups. Disease Markers 5: 153-164

51. Sakurami T, Ueno Y, Nagaoka K, Kuno S, Iwaki Y, Park MS, Terasaki PI (1982) HLA-DR specifications in Japanese with juvenile-onset insulin-dependent diabetes mellitus. Diabetes 31 : 105-106

52. Kobayashi T, Sugimoto T, Itoh T, Kosaka K, Tanaka T, Suwa S, Sato K, Tsuji K (1986) The prevalence of islet cell antibodies in Japanese insulin-dependent and non-insulin-dependent diabetic patients studied by indirect immunofluorescence and by a new method. Diabetes 35: 335-340

53. Ito $M$, Tanimoto $M$, Kamura $H$, Yoneda M, Morishima $Y$, Takatsuki K, Itatsu T, Saito H (1988) Association of HLA-DR phenotypes and T-lymphocyte-receptor $\beta$-chain-region RFLP with IDDM in Japanese. Diabetes 37: 1633-1636

54. Aparicio JMR, Wakisaka A, Takada A, Matsuura N, Aizawa M (1988) HLA-DQ system and insulin-dependent diabetes mellitus in Japanese: does it contribute to the development of IDDM as it does in Caucasians? Immunogenetics 28: 240-246

55. Owerbach D, Lernmark $\AA$, Platz P, Ryder LP, Peterson PA, Ludvigsson J (1983) HLA-D region $\beta$-chain DNA endonuclease fragments differ between HLA-DR identical healthy and insulin-dependent diabetic individuals. Nature 303: 815-817

56. Kim SJ, Holbeck SL, Nisperos B, Hansen JA, Maeda H, Nepom GT (1985) Identification of a polymorphic variant associated with HLA-DQw3 and characterised by specific restriction. sites within the DQ $\beta$-chain gene. Proc Natl Acad Sci USA 82: 8139-8143

57. Nepom BS, Palmer J, Kim SJ, Jansen JA, Holbeck SL, Nepom GT (1986) Specific genomic markers for the HLA-DQ subregion discriminate between DR4+ insulin-dependent diabetes mellitus and DR4 + seropositive juvenile rheumatoid arthritis. J Exp Med 164: 345-350

58. Todd JA, Fukui Y, Kitagawa T, Sasazuki T (in press) The A3 allele of the HLA-DQA1 locus is associated with susceptibility to Type 1 diabetes in Japanese. Proc Natl Acad Sci USA

59. Sheehy MJ, Scharf SS, Rowe JR, Neme de Gimenez MH, Meske LM, Erlich HA, Nepom GT (1989) A diabetes susceptibility HLA haplotype is best defined by a combination of HLADR and DQ alleles. J Clin Invest 83: 830-835

60. Owerbach D, Gunn S, Gabbay KH (1989) Primary association of HLA-DQw8 with Type 1 diabetes in DR4 patients. Diabetes 38: 942-945

61. Cohen N, Brautbar C, Font M-P, Dausset J, Cohen D (1986) HLA-DR2-associated Dw subtypes correlate with RFLP clus- ters: most DR2 IDDM patients belong to one of these clusters. Immunogenetics 23: $84-89$

62. Field LL (1989) Genes predisposing to insulin-dependent diabetes in multiplex families. Genet Epidemiol 6: 101-106

63. Dunston GM, Henry LW, Christian J, Ofosu MD, Callender CO (1989) HLA-DR heterogeneity in American Blacks is associated with susceptibility and resistance to insulin-dependent diabetes mellitus. Transplant Proc 21: 653-655

64. Hurley CK, Gregersen PK, Gorski J, Steiner N, Robbins FM, Hartzmann R, Johnson AH, Silver J (1989) The DR3(w18), DQw4 haplotype differs from DR3(w17), DQw2 haplotypes at multiple class II loci. Hum Immunol 25:37-50

65. Morel PA, Dorman JS, Todd JA, McDevitt HO, Trucco M (1988) Aspartic acid at position 57 of the HLA-DQ $\beta$ chain protects against diabetes: a family study. Proc Natl Acad Sci USA 85: $8111-8115$

66. Bao MZ, Wang JX, Dorman JS, Trucco (1989) HLA-DQß nonAsp-57 allele and incidence of diabetes in China and the USA. Lancet II: 497-498

67. Hitman GA, Sachs J, Cassell P, Awad J, Bottazzo GF, Tarn AC, Schwartz G, Monson JP, Festenstein H (1986) A DR3-related DX $\alpha$ gene polymorphism strongly associates with insulin-dependent diabetes mellitus. Immunogenetics 23: 47-51

68. Mandrup-Poulsen T, Bendtzen K, Dinarello CK, Nerup J (1987) Human tumour necrosis factor potentiates human interleukin-1 mediated rat pancreatic B-cell cytotoxicity. J Immunol 139: 4077-4082

69. Badenhoop K, Schwarz G, Trowsdale J, Lewis V, Usadel KH, Gale EAM, Bottazzo GF (1989) TNF- $\alpha$ polymorphism in Type 1 (insulin-dependent) diabetes mellitus. Diabetologia 32: 445-448

70. Jackson RA, Morris MA, Hayes DF, Eisenbarth GS (1982) Increased circulating Ia antigen-bearing T-cells in Type 1 diabetes mellitus. N Engl J Med 306: 785-788

71. Miller BJ, Appel MC, O'Neill JJ, Wicker LS (1988) Both the Lyt-2 + and L3T4 + T cell subsets are required for the transfer of diabetes in nonobese diabetic mice. J Immunol 140: 52-58

72. Bill J, Kanagawa O, Woodland DL, Palmer E (1989) The MHC molecule I-E is necessary but not sufficient for the clonal delection of Vß11-bearing T cells. J Exp Med 169: 1405-1419

73. Segall M (1988) HLA and genetics of IDDM. Holism vs reductionism? Diabetes 37: 1005-1008

Dr. A.H. Barnett

East Birmingham Hospital

Bordesley Green East

Birmingham B9 5ST

UK 